\title{
History of marine biological investigations in Poland
}

\author{
M. Maciejowska \\ Polish Academy of Sciences, Marine Biology Centre; św. Wojciecha 5, 81-347 Gdynia, \\ Poland
}

The second half of the 19th century and the early years of the 20th witnessed an intensive development of modern oceanography strictly connected with marine biology research. At that time, a number of European countries were arranging overseas expeditions across the ocean and were founding coastal laboratories in order to improve biological investigation methods. This was the period of Poland's slavery which had excluded the "country of the sea" and the possibility of self-management. At that time, Polish biologists were only able to broaden their scientific knowledge by working at foreign marine stations or universities, and by taking part in ocean expeditions - as did Professors Kwietniewski, H. Arctowski, A. B. Dobrowolski, and others.

After Poland had regained its independence, and thus the access to the Baltic Sea, people grew more interested in marine problems. In 1923, a Marine Fisheries Laboratory in Hel came into being through a ministry decree of the former Prussian Province. The head of this Lab was Dr. K. Demel. Despite primitive equipment and severe living conditions, especially in winter, several research works were done on hydrography, biology, and fisheries, presenting the marine environment around Hel. In 1932 (also in Hel), SFI was turned into the Marine Station - which had a broader marine biological and fisheries programme. It was made a part of the Nencki Experimental Biology Scientific Institute, with Dr. M. Bogucki in charge. The Marine Station operated in Hel until the end of 1938 (Figs 1,2). It was transferred to Gdynia in 1939, where it was housed in a specially constructed and well-equipped building. The Station's research programme was aligned with the programme of the International Sea Research Council in Copenhagen. Poland had joined the Council and placed official government delegates there: Professor Michal Siedlecki from Kraków and Drs. J. Borowik and F. Lubecki. The activity range of the Station was aimed at thoroughly learning about the Baltic Sea, especially its southern areas. The team was made up of specialized scientists and consisted of a physiologist, a zoologist, an algologist, a planktologist, a hydrographist and a few ichtyologists. The Station performed programme voyages in the Baltic, and courses in marine investigation methodology. The numerous investigation results - very interesting as they were - were published in the Bulletin and works of the Marine Station. Other biologists, active in different fields, visited the station in summer. The outbreak of World War II in 1939 wrecked its active start and promising development.

It was only after the war that the Station was reactivated under a new name: Marine Fisheries Laboratory. 


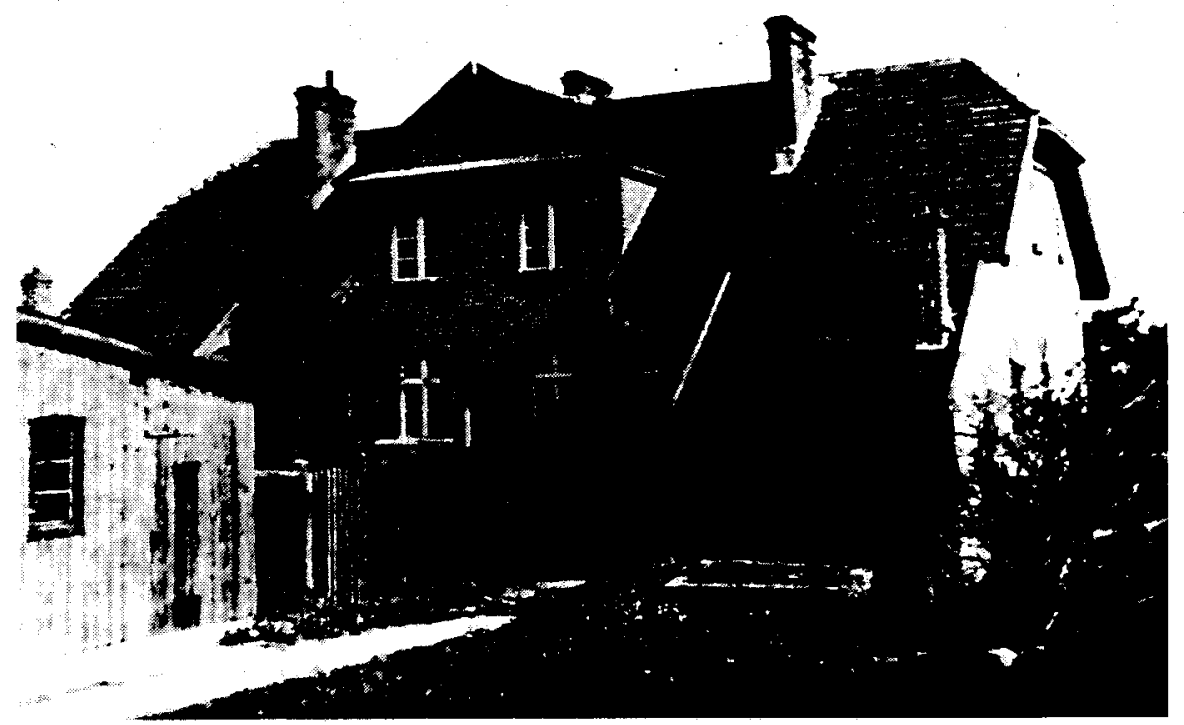

Fig. 1. Marine Station in Hel, around 1937

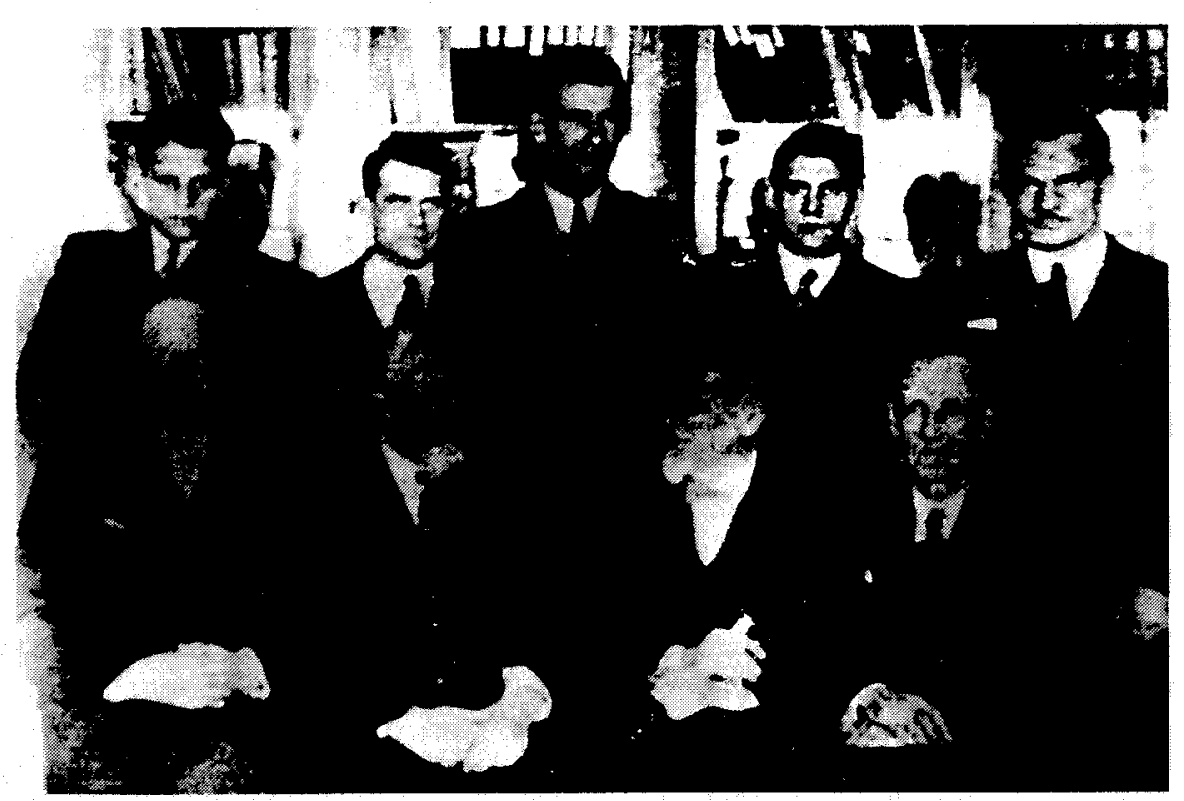

Fig. 2. Marine Station staff: standing, from the left: W. Cięglewicz, A. Bursa, W. Mańkowski, S. Kijowski, Z. Mulicki; seated, from the left: B. Dixon, M. Bogucki, M. Siedlecki, K. Demel 
In 1949, the Marine Fisheries Laboratory was incorporated into the Association of the Sea Fisheries Institute (the SFI) thus forming a highly-ranked institute (Fig. 3). Apart from a practical fisheries programme, the Sea Fisheries Institute largely carried out oceanography and biology investigations. In 1949, the SFI opened an ichtyological institute on the Szczecin Lagoon in Swinoujście and another one in Kołobrzeg.

The years 1945-1958 were busy reconstructing and arranging the scientific potential. Ecological investigations on the Baltic then aimed at showing the influence of physicochemical conditions on the biocenosis of its ecosystems. Broadened investigations on the biology of Baltic fishes were also carried out. Beginning in 1954 Poland had resumed research in the North, thanks to a ship M.T. "Birkut" which was acquired by the SFI. Every spring and autumn the Institute performed investigations on zooplankton and ichtyoplankton biomass (mainly in the North Sea) which, among others, was included in the ICES programme.

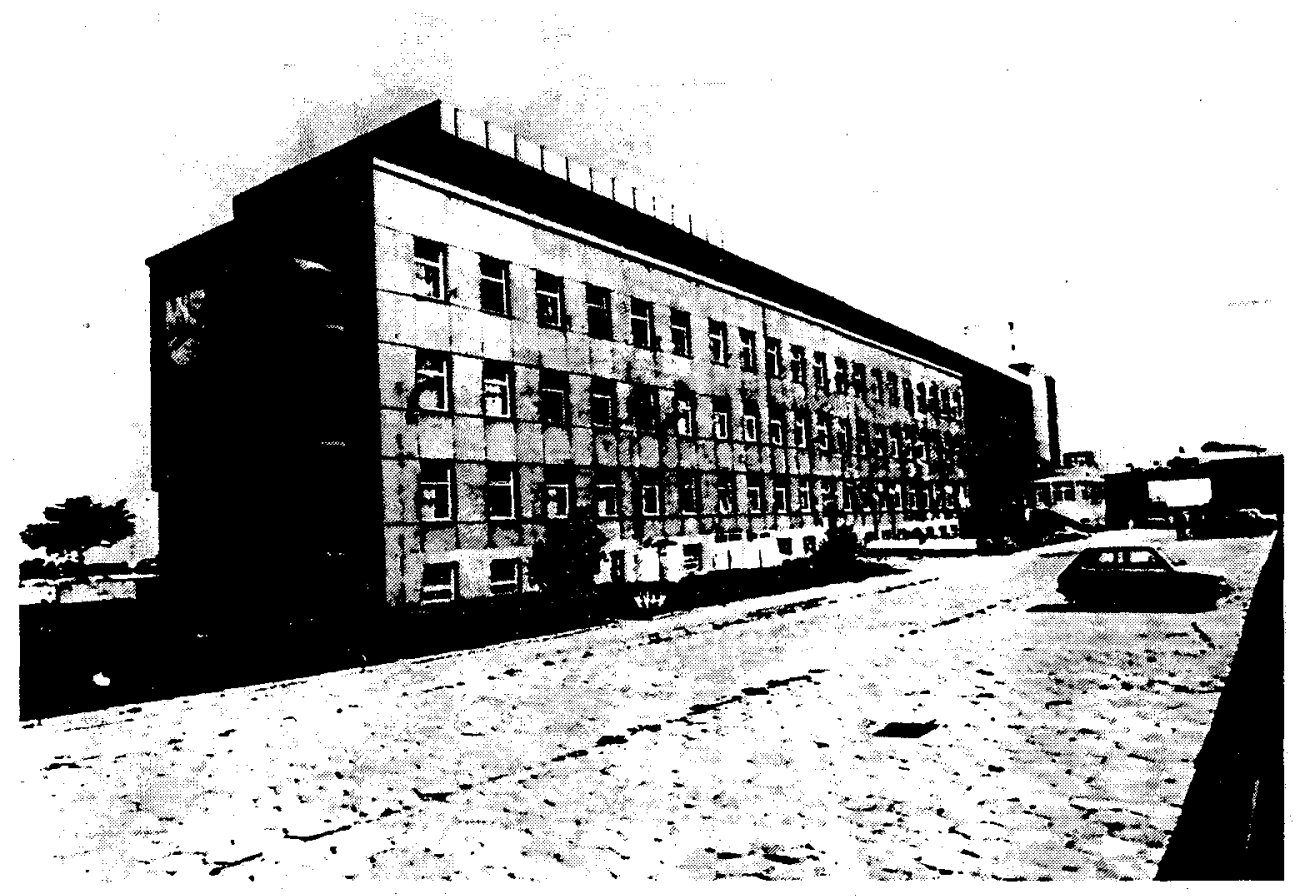

Fig. 3. The edifice of the Sea Fisheries Institute, founded in 1939, with the museum and marine aquarium

The period 1958-1968 was the time during which particular trophic links of marine life were studied, along with ecological investigations, including primary production.

Between 1968 and 1979, new trends in secondary biological production were introduced embracing zooplankton, zoobenthos and Baltic fishes. The target was to establish the Baltic biological production in absolute values, and its estimation from particular trophic net links. 
Since 1970 there has been an explosion of basic and applied investigations in all Polish scientific centres, including those oceanographic and biological ones. Over this time the Polish Academy of Sciences (PAS - its Institute of Ecology based in Dziekanów Leśny, near Warsaw) ordered the Oceanography Laboratory of the SFI to investigate the Baltic ecosystem production (1971-1975). This was a complex task, employing all the major oceano-biological and physical teams of Poland. The 5 year research resulted in first of all establishing hydrobiological conditions fluctuations and their influence on the Baltic biocenosis and biological production, as well as biological production and biomass size estimation. It was this research that has been material for the works of the Gdańsk and Helsinki Conventions, in the field of Baltic resources and marine environment protection.

Due to another ocean research vessel "Prof. Siedlecki" (Fig. 4) that the SFI acquired in 1972, Polish scientists were able to expand their investigation area across the Atlantic, the Pacific, the Indian Ocean, and the Arctic and Antarctic, which meant almost the entire high seas. The results were imposing, giving a broad overview and insight into the biology and ecology of the sea, ecophysiology and bioenergetics of marine organisms, biological production, and also resources estimation - especially of the investigated seas' and oceans' depths.

Another scientific unit has recently been opened in the SFI, the "Plankton Sorting and Identification Centre" in Szczecin - a part of the Polish-American cooperation project. It mainly works on material brought from the American parts of the Atlantic and

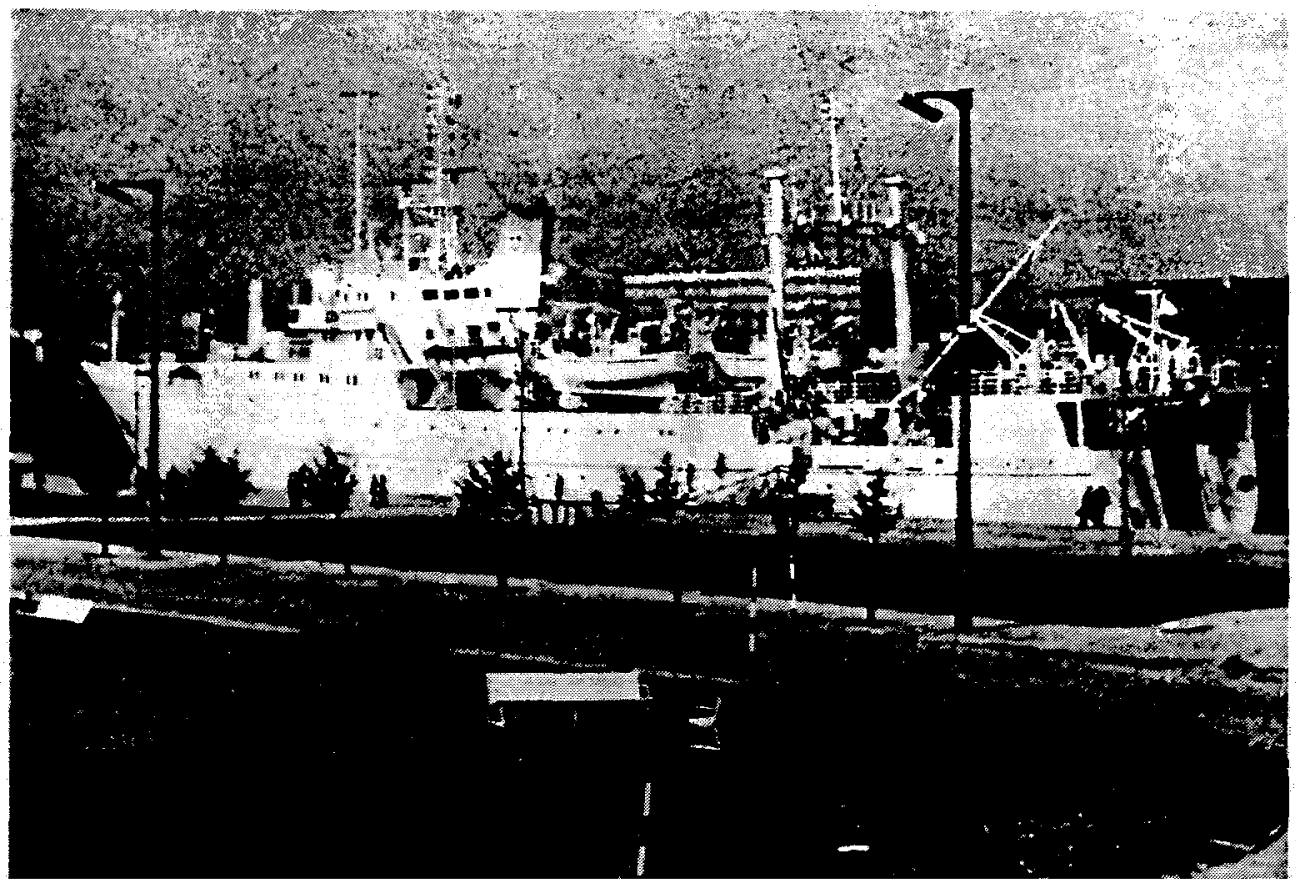

Fig. 4. The research vessel of the Sea Fisheries Institute R.V. "Profesor Siedlecki" 
the Pacific. The Centre's main task is to sort and determine marine plankton, including ichtyoplankton.

In 1991 the SFI celebrated its 70th anniversary in a newly-built edifice in Kolłata street in Gdynia. This year the Institute received a new research vessel for the Baltic investigation, the R.V. "Baltica".

Another centre occupied with ocean research is the Ecology Institute of the Polish Academy of Sciences in Warszawa-Dziekanów. The Institute's scientists take part in regular experiments at the Polish Arctic station (Fig. 5) and the Antarctic research station "Henryk Arctowski". Research on the Antarctic base has been closely connected to

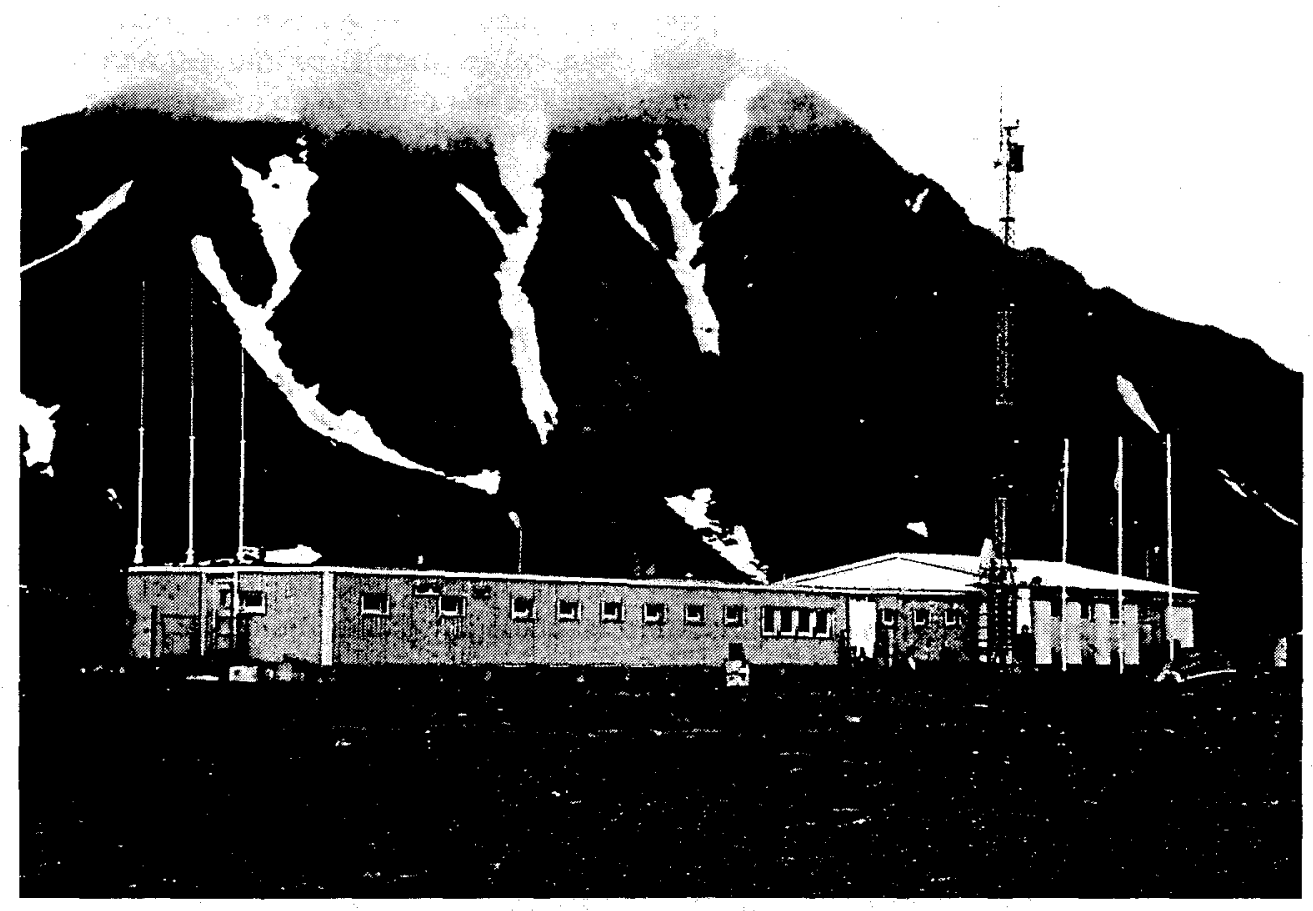

Fig. 5. Polish Polar Station in Hornsund, Spitzbergen

international scientific programmes coordinated by SCAR (Scientific Committee on Antarctic Research), such as BIOMASS (Biological Investigations of Marine Antarctic Systems and Stocks), EA.SIZ (Ecology of the Antarctic Sea-Ice-Zone) as well as GLOBAL CHANGE-oriented projects. The Polish Academy of Sciences supervises a comprehensive research programme with the purpose of an investigation of the Polar natural environment for a better understanding of its functioning, conservation, and rational use of its resources. The programme of the PAS covered, i.a., the investigation of marine animals' bioenergetics and ecophysiology. Since 1980, the results have been published in the quarterly "Polish Polar Research".

Apart from the ones mentioned, a number of minor stations exist in Poland, performing a narrower range of study, but nevertheless crucial for the marine environment. One 
of them is the Fisheries Oceanography and Sea Protection Institute being supervised by the Agricultural Academy in Szczecin. The Institute is mainly concerned with marine biology with an emphasis on zoobenthos, zooplankton and bioenergetics, as well as the Baltic coastal-zone pollution. They have also been controlling the Odra estuary, by zooplankton and meiobenthos succession study.

For the last 20 years, the Institute of Oceanology of the Polish Academy of Sciences in Sopot has been occupied mainly with physical oceanography, and marine biology as well. Being the owner of a research vessel "Oceania", the research teams are able to reach the waters of the Antarctic, Spitzbergen, the Norwegian Sea, the Barents Sea, and certainly the Baltic, where they carry out investigations on phytoplankton and zooplankton. In order to obtain data on the sea's primary production, the teams have been taking into account physical (mainly the light) and chemical (nutrients) conditions, and trace metal pollution. Biologically active substances from the sea undergo an analysis from the point of view of medical application. Another problem being worked on by the Institute is the impact that humus substances have on bloom intensity.

Investigations carried out for 25 years by the Institute of Oceanography of the Gdańsk University have made marine ecosystems more understandable, with special attention paid to ecosystem functioning under anthropo-oppressive conditions. Marine organisms' biology and ecology have been analysed for many years; also, ecophysiological study of marine algae from the production point of view. Besides this, polar areas have been visited such as the Antarctic and Spitzbergen for population and bioenergetical investigations.

The Institute of Genetics of the Gdańsk University has been working on population genetics of some copepods and crustaceans in the Baltic Sea and the Arctic zone.

Parasitic copepods and isopods of fish from the Atlantic and Pacific Oceans have been studied in the Department of Invertebrate Zoology. At the Biological Station in Gdańsk - Górki Wschodnie (established in 1955) - the main scientific research has been devoted to comparative endocrinology and biochemistry of marine animals.

The Environment Protection Institute in Gdynia, established in 1976, has been conducting biological monitoring in the open Baltic and in the coastal zone, thus fulfilling the regulations of the Helsinki Convention which was ratified by Poland.

The Marine Biology Centre of the Polish Academy of Sciences was established in 1989, with the task of developing marine investigations in the fields not sufficiently covered by other institutions. Thus, marine microbiology, genetics and ecological physiology are represented, together with selected topics of ecology (e.g. seston, relict benthic fauna). The youngest Polish marine research unit is open for cooperation with related European institutions.

Scientific institutes in Poland are established by different ministries which impose their requirements, in terms of scientific activities. Hence their research ranges are simultaneously various and incoherent. There is a strong need to coordinate the system of scientific research - paying special attention to the Baltic ecosystems.

Generally, Polish scientific institutes have been facing financial difficulties for some time now, which, within the next 5 years, may result in equipment, research vessels and arctic stations decapitation. Nevertheless, the scientists constitute perfect teams of marine biology specialists, and use modern laboratory equipment; therefore they are ready to cooperate with scientists abroad, especially from countries in a "united Europe". 